\title{
Work begins on state of the art new facility
}

On 14 December the University College London Hospitals NHS Foundation Trust (UCLH) began building a new clinical facility for services from the Royal National Throat, Ear and Nose Hospital (RNTNEH) and Eastman Dental Hospital (EDH). The new facility will be situated on Huntley Street and will cost $£ 104$ million.

When it opens, the facility will provide ear, nose, throat and dental services from a state of the art building in Central London, enabling patients to receive integrated and multidisciplinary care in a location close to the UCL and UCLH campuses.

A patient from both the RNTNEH and the EDH attended a ceremony to mark the first day of construction. They were joined by UCLH chairman Richard Murley, UCLH interim chief executive Neil Griffiths and Mace deputy chief operating officer for construction Mark Castle to mark a new chapter in the history of the two hospitals which, together, go back more than 220 years.

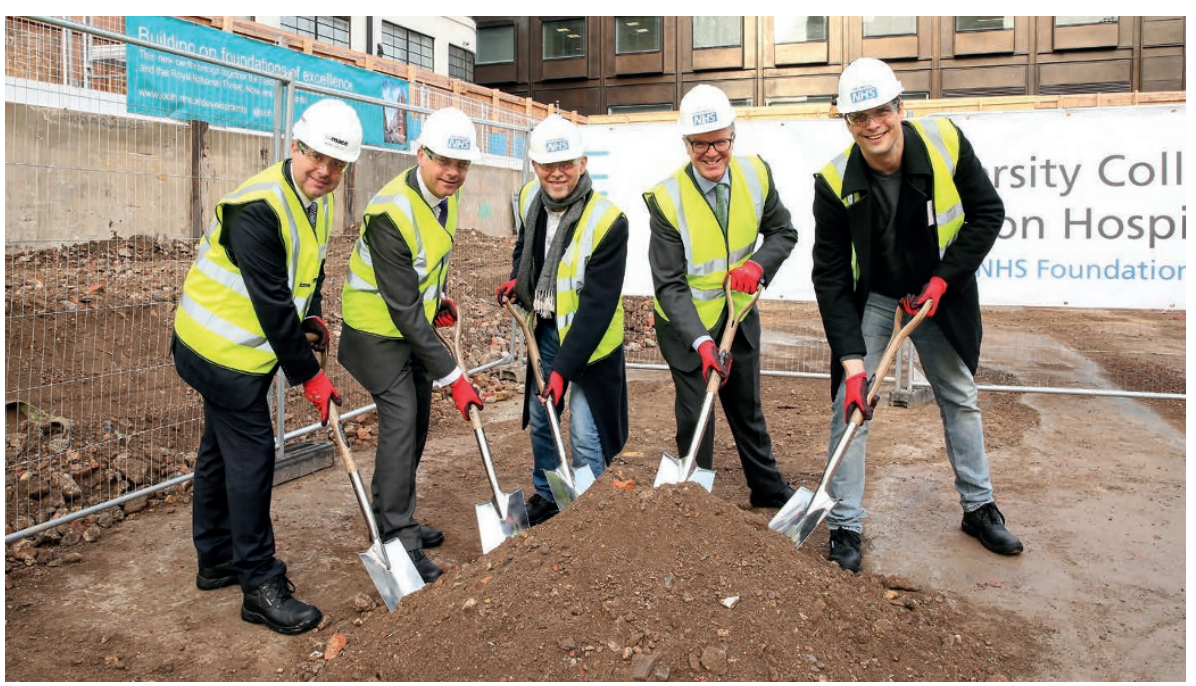

The Huntley site previously housed the Royal Ear Hospital and the UCL medical students union.

The build will take around 30 months to complete and at its peak, there will be around 240 construction staff on the site. Heritage is a key theme in the new facility, with the façade including the Duveen Memorial stone from the Royal Ear Hospital and an arts and heritage project developing material from the two hospitals for the interior of the new facility. 